\title{
ANALISIS PENGELOLAAN BERAS SEMI ORGANIK DI KABUPATEN OKU TIMUR
}

\author{
(Munsiarum)
}

\begin{abstract}
The purpose of this research were to: (1) To determine the level of production costs and revenue from the management of semi-organic rice in East OKU District, (2) To analyze whether the management of semi-organic rice in East OKU District to develop. This research was conducted in 3 villages namely Karang Sari, Tegal Rejo, and Sumbersuko. The location determination is done intentionally (purposive) because in the village there is the management of organic rice. The research was conducted in May 2013. The study found that the average total cost of production which acquired the generated business in the year to 1 reception $R p 9.342$ million, - / Process, a fee of $R p$ 4,771,679, - / process then revenue Rp 4,570,303, - I process. Enterprises in the year to 2 reception $R p 10.0602$ million, - / Process, a fee of Rp 4,657,624, - I process the revenue of $R p$ 5,402,576, - / process. Enterprises in the year to 3 reception Rp 13.75 million, - I Process, a fee of $R p$ 4,675,274, - / process, the revenue of $R p$ 9,074,726, - / process. Enterprises in the year to 4 reception $R p 20.4$ million, - / processes, costs $R p$ 4,681,574, - / process, the revenue of $R p$ 15,718,426, / process and NPV values obtained Comfounding lowest factor of 18\% amounting to Rp 25 854 .258, - / 4 years, the value NPVN Comfounding highest factor of $30 \%$ was obtained at a negative value - Rp 1,661,258, - / 4 years with an IRR obtained $29.28 \%$ and Net B / C gained 1.26, then attempt profitable and feasible to be developed and passed.
\end{abstract}

Key Words : Organic Rice, Income.

\section{PENDAHULUAN}

\section{A. Latar Belakang}

Revolusi hijau merupakan usaha yang dilakukan manusia dalam meningkatkan produksi pangan dengan jalan melakukan pengembangan pada teknologi pertanian untuk mencukupi kebutuhan pangan dan kesejahteraan penduduk dunia. Hasil pertanian yang di dapat dari program BIMAS tersebut memang sangat menguntungkan, namun metode pertanian yang diterapkan untuk memenuhi kebutuhan pangan masyarakat Indonesia masih terus dipertanyakan. Hal ini dikarenakan adanya beberapa akibat yang ditimbulkan, seperti menurunnya produktivitas tanah akibat penggunaan pupuk kimia secara berlebihan dan rusaknya keseimbangan ekosistem akibat penggunaan pestisida yang tanpa disadari akan mengakibatkan matinya spesies lain selain hama dan penyakit tanaman. Selain itu, untuk memenuhi kebutuhan penggunaan pupuk dan pestisida anorganik maka petani memerlukan biaya yang relatif mahal sehingga akan berimplikasi pada semakin meningkatnya biaya produksi yang dikeluarkan (Winangun, 2005).

Dunia usaha pertanian saat ini dihadapkan pada dilema yaitu mengenai apakah akan tetap mempertahankan pola pengelolaannya seperti saat ini dengan menggunakan lebih banyak input luar (obat- obatan dan pupuk buatan) atau dengan menggunakan lebih banyak input dalam (kompos, pupuk kandang dan obat-obatan alami). Dua pilihan ini sama-sama memiliki kelebihan dan kekurangan masing-masing dan bila dipilih memiliki bobot pilihan yang seimbang. Jika memilih dengan lebih banyak menggunakan input luar, dalam jangka pendek kebutuhan akan hasil-hasil pertanian akan dapat dipenuhi, akan tetapi dalam jangka panjang akan mengalami penurunan yang drastis akibat kerusakan lingkungan yang ditimbulkannya. Sebaliknya, jika memilih pada penggunaan input dalam yang lebih banyak, maka dalam jangka pendek kebutuhan akan hasil-hasil pertanian tidak dapat dipenuhi. Namun, dalam jangka panjang akan menjamin terpenuhinya kebutuhan akan hasil-hasil pertanian secara berkesinambunan(Winangun, 2005).

Tabel 1.Konsumsi Beras per Kapita per Tahun di Kabupaten OKU Timur Tahun 2009-2013

\begin{tabular}{ccccc}
\hline $\begin{array}{c}\text { Tah } \\
\text { un }\end{array}$ & $\begin{array}{c}\text { Produk } \\
\text { si } \\
\text { GKG(t } \\
\text { on) }\end{array}$ & $\begin{array}{c}\text { Beras } \\
(\mathrm{kg})\end{array}$ & $\begin{array}{c}\text { Pendu } \\
\text { duk } \\
\text { (jiwa) }\end{array}$ & $\begin{array}{c}\text { Konsumsi } \\
\text { beras/tahun/k } \\
\text { g/jiwa }\end{array}$ \\
\hline 201 & 47.578 & 28.856. & 330.02 & 87,44 \\
1 & & 420 & 5 & \\
201 & 51.480 & 31.223. & 335.09 & 93,18 \\
2 & & 010 & 4 & \\
201 & 55.372 & 33.583. & 339.93 & 98,78 \\
3 & & 540 & 7 & \\
\hline
\end{tabular}




\begin{tabular}{ccccc}
\hline 201 & 61.524 & 37.34 .7 & 344.93 & 108,18 \\
4 & & 70 & 2 & \\
201 & 54.496 & 33.052. & 349.80 & 94,49 \\
5 & & 240 & 0 & \\
\hline
\end{tabular}

Sumber : BPS OKU Timur.

Dari data diatas dapat dlihat bahwa Kabupaten OKU Timur kebutuhan beras semakin meningkat tiap tahunnya. Pertanian konvensional pun juga semakin bertambah. Perhatian masyarakat dunia terhadap persoalan pertanian dan lingkungan global beberapa tahun ini menjadi meningkat. Kepedulian tersebut dilanjutkan dengan melaksanakan usaha-usaha yang terbaik untuk menghasilkan pangan tanpa menyebabkan terjadinya kerusakan sumber daya tanah, air dan udara. Salah satu usaha yang dirintis adalah pengembangan pertanian organik yang akrab lingkungan dan menghasilkan pangan yang sehat (bebas dari obat-obatan dan zat-zat kimia yang mematikan). Sebenarnya, pertanian organik ini sudah menjadi kearifan/pengetahuan tradisional yang membudaya di kalangan kaum tani di Indonesia, namun teknologi pertanian organik ini mulai ditinggalkan oleh petani ketika intensifikasi yang mengandalkan bahan agrokimia diterapkan dibidang pertanian pada era revolusi hijau. Setelah muncul persoalan dampak lingkungan akibat penggunaan bahan kimia dibidang pertanian, teknologi pertanian organik yang akrab lingkungan dan menghasilkan pangan yang sehat mulai diperhatikan lagi (Sutanto, 2002).

Secara khusus, pertanian organik dimaksudkan untuk menghasilkan makanan bermutu tinggi dan bergizi yang mendukung pemeliharaan kesehatan dan kesejahteraan. Mengingat hal tersebut, maka harus dihindari penggunaan pupuk, pestisida, obat - obatan bagi hewan dan aditif makanan yang dapat berefek merugikan kesehatan. Dengan mengkonsumsi beras organik dapat menurunkan kadar gula dalam darah, bagi penderita diabetes memakan beras organik dapat menurunkan kadar gula. Sehinga beras organik mempunyai manfaat bagi kesehatan masyarakat. Pengembangan pertanian organik harus mengacu kepada prinsip-prinsip organik (prinsip kesehatan, prinsip ekologi, prinsip keadilan, dan prinsip perlindungan) agar mendapatkan hasil pangan yang bermutu serta aman di konsumsi. Di Sumatera Selatan pertanian organik mulai berkembang, hampir disetiap kabupaten mulai mengusahakan pertanian organik, tanaman yang dihasilkan yaitu beras organik. OKU Timur sebagai salah satu kabupaten penghasil beras terbesar di provinsi Sumsel, saat ini mulai melirik mengembangkan padi organik . Meskipun dilapangan, pertanian organik tersebut masih semi organik . Tapi sedang diusahakan untuk sertifikasi dan perbaikan, untuk menciptakan beras organik seutuhnya.

\section{B. Rumusan Masalah}

1. Berapa besar biaya produksi dan pendapatan dari usaha pengelolaan beras semi organik di Kabupaten OKU Timur.

2. Bagaimana kelayakan usaha pengelolaan beras semi organik di Kabupaten OKU Timur.

\section{Tujuan dan Kegunaan}

1. Untuk mengetahui besarnya biaya produksi dan pendapatan dari pengelolaan beras semi organik di Kabupaten OKU Timur.

2. Untuk menganalisis apakah pengelolaan beras semi organik di Kabupaten OKU Timur layak untuk dikembangkan.

\section{Model Pendekatan}

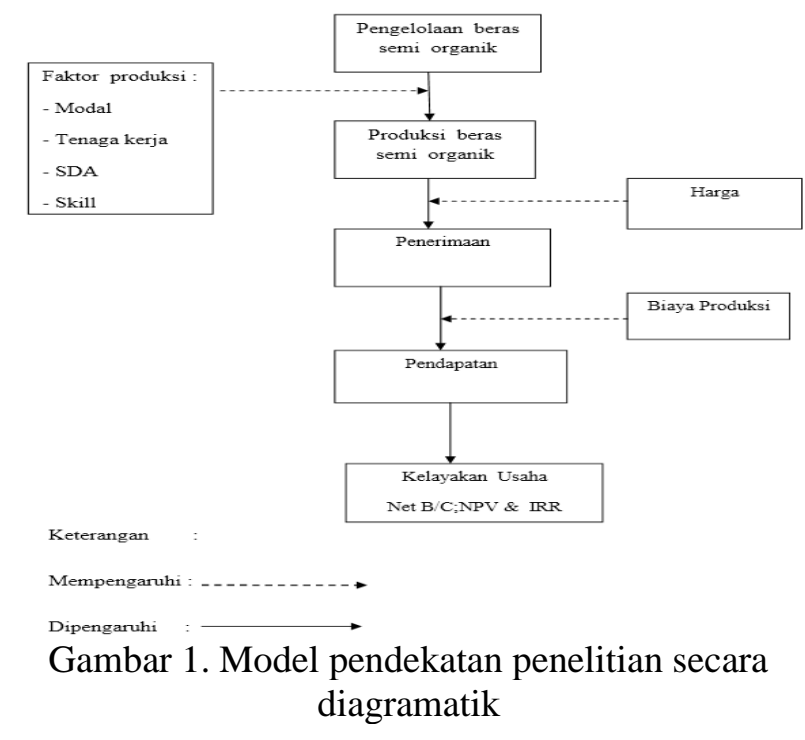

\section{METODOLOGI PENELITIAN}

\section{A. Tempat dan Waktu}

Penelitian ini dilakukan pada 3 Desa yaitu Karang Sari, Tegal Rejo, dan Sumbersuko. Penentuan lokasi dilakukan secara sengaja (purposive) karena di Desa tersebut terdapat pengelolaan beras organik. Penelitian ini dilaksanakan pada Bulan Mei 2013. 


\section{B. Metode Penelitian}

Metode penelitian yang akan digunakan dalam penelitian ini adalah metode survei. Menurut Walgito (2009), survei adalah mengumpulkan informasi berbentuk opini dari sejumlah besar orang terhadap topik atau isu-isu tertentu. Ada 3 karakter utama dari survei : 1) informasi dikumpulkan dari sekelompok besar orang untuk mendeskripsikan beberapa aspek dan karakteristik tertentu seperti : kemampuan, sikap, kepercayaan, pengetahuan dari populasi; 2) informasi dikumpulkan melalui pengajuan pertanyaan (umumnya tertulis bisa juga lisan) dari suatu populasi ; 3) informasi diperoleh dari sampel, bukan dari populasi. Tujuan utama dari survei adalah mengetahui gambaran umum karakteristik dari populasi atau sampel.

\section{Metode Penarikan Contoh}

Metode penelitian yang akan digunakan dalam penelitian ini adalah metode sampling 30 responden dari 3 populasi, dimana Populasi berasal dari berbagai kecamatan yang ada di OKU Timur.

Tabel 2. Populasi jumlah desa, jumlah petani dan luas garapan.

\begin{tabular}{lcc}
\hline \multicolumn{1}{c}{ Desa } & $\begin{array}{c}\text { Jumlah } \\
\text { Petani }\end{array}$ & $\begin{array}{c}\text { Luas } \\
\text { Garapan } \\
\text { ( bahu) }\end{array}$ \\
\hline Karang sari & 12 & 3,5 \\
Tegal rejo & 1 & 1 \\
Sumbersuko & 17 & 6 \\
\hline 3Data & 30 & 11,51 \\
\hline
\end{tabular}

Sumber : Olahan data primer,2013.

\section{Metode Pengolahan Data}

Data yang diperoleh dari penelitian akan dikelompokkan dan kemudian diolah menggunakan metode matematis yang dibantu dengan program komputer dengan bantuan software Microsoft excel yang akan di tampilkan dalam bentuk tabulasi sehingga dapat dijelaskan secara deskriptif kuantitatif. Untuk menjawab tujuan dari penelitian yaitu besar biaya produksi dan pendapatan.

a.Untuk mengetahui biaya produksi (Soekartawi, 2002), dengan rumus : $\mathrm{TC}=\mathrm{FC}+\mathrm{VC}$

Dimana :

$\mathrm{TC}=$ Total Cost (Rp/proses)

$\mathrm{FC}=$ Fixed Cost (Rp/proses)

$\mathrm{VC}=$ Variable Cost $(\mathrm{Rp} /$ proses $)$ b. Untuk mengetahui penerimaan digunakan rumus :

$$
\mathrm{TR}=\mathrm{Q} \times \mathrm{P}
$$

Dimana :

$\mathrm{TR}=$ Total Reveneus $(\mathrm{Rp} / \mathrm{proses})$

$\mathrm{Q}=$ Quantity $(\mathrm{Kg} /$ Proses $)$

$\mathrm{P}=$ Price $(\mathrm{Rp} / \mathrm{Kg})$

c.Untuk menghitung pendapatan digunakan rumus :

$$
\pi=\mathrm{TR}-\mathrm{TC}
$$

Dimana :

$\pi=$ Income $(\mathrm{Rp} /$ Proses $)$

$\mathrm{TR}=$ Total Revenues $(\mathrm{Rp} / \mathrm{Proses})$

$\mathrm{TC}=$ Total Cost $(\mathrm{Rp} /$ Proses $)$

Untuk menjawab tujuan kedua yaitu analisis kelayakan finansial:

a. Untuk menghitung NPV maka menggunakan rumus (Zulkarnain Djamin, 1993) yaitu:

$$
\left.\mathrm{NPV}=\left[\sum_{t=i}^{t=n} \frac{b t-c t}{(1+i) t}\right]-K o\right]
$$

Keterangan:

$\mathrm{b}_{\mathrm{t}}=$ benefit kotor setiap tahunnya.

$\mathrm{c}_{\mathrm{t}}=$ annual cost

$(1+\mathrm{i})^{\mathrm{t}}=$ Discounting factor

Ko $=$ initial invesment

$\mathrm{t}=\mathrm{n}$.umur ekonomis proyek

$\mathrm{t}=1$, tahun pertama proyek

Dengan kriteria :

NPV > 0 maka usaha layak dikembangkan NPV $<0$ maka usaha tidak layak untuk dikembangkan

NPV $=0$ maka usaha dalam keadaan impas b.Untuk menghitung Internal Rate Ratio (IRR) maka digunakan rumus: sebagai berikut:

$I R R=D F P+\left\{\frac{P V P_{1}}{((P V P)-(P V N))} X(D F N-D F P)\right\}$

Keterangan:

$\mathrm{D}_{\mathrm{F}} \mathrm{P}=$ discounting faktor yang digunakan menghasilkan present value positive $\mathrm{D}_{\mathrm{F}} \mathrm{N}=$ discounting faktor yang digunakan menghasilkan present value negative $\mathrm{PVP}=$ Present Value Positive $\mathrm{PVN}=$ Present Value Negative c.Untuk menghitung nilai $\mathrm{Net} \mathrm{B} / \mathrm{C}$ ratio maka digunakan rumus :

$$
\text { Net } \frac{B}{C}=\frac{\left.\sum\left(\sum_{t=1}^{t=n}\left(\frac{b t}{d 1+\hat{D}} t\right)\right)\right)}{\left.\sum_{t=i}^{t=n}\left(\frac{c t}{[1+\hat{D} t}\right)+K o\right)}
$$

Keterangan:

$\mathrm{Bt}=$ Benefit (penerimaan kotor pada tahun ke-t)

$\mathrm{Ct}=$ Cost (biaya kotor pada tahun ke-t) 
$\mathrm{n}=$ umur ekonomis proyek

$\mathrm{i}=$ tingkat suku bunga yang berlaku

$\mathrm{Ko}=$ Cost

Dimana :

Net $B / C>0$, Berarti usaha tersebut layak dikembangkan

Net $\mathrm{B} / \mathrm{C}=0$, Berarti usaha tersebut tidak untung tidak rugi

Net $\mathrm{B} / \mathrm{C}<0$, Berarti usaha tidak layak dikembangkan

\section{HASIL DAN PEMBAHASAN}

\section{A. Analisis Biaya Usaha}

\section{Analisis Penggunaan Biaya}

Biaya merupakan faktor-faktor atau korbanan yang digunakan untuk memperoleh suatu manfaat atau keuntungan, biaya terbagi atas 3 sub yaitu biaya penggunaan alat-alat usaha atau biaya tetap (Fixed Cost), dimana besar kecilnya biaya tetap tidak mempengaruhi terhadap jumlah produksi. Selain biaya tetap terdapat biaya tidak tetap (Variabel Cost), biaya tidak tetap pada umumnya biaya-biaya yang termasuk seperti biaya jasa traktor, perbaikan pematang, pemupukan dan aplikasi poc. Biaya tidak tetap adalah biaya yang jumlah dapat mempengaruhi jumlah produksi yang dihasilkan.selain biaya tetap dan biaya tidak tetap terdapat juga biaya tenaga kerja.

\section{a. Analisis Biaya Tetap Usaha}

Penggunaan biaya tetap pada usaha pengolahan rumah knock down adalah biaya penggunaan berupa alat-alat seperti penggunaan cangkul, sabit, ember, dan rolli. Rata-rata penggunaan biaya tetap pada usaha pengelolaan beras semi organik di Kabupaten OKU Timur. sebagaimana pada tabel berikut :

Tabel 3. Rata-rata Penggunaan Biaya Investasi dan Biaya Tetap Usaha Pengelolaan Beras Semi Organik di Kabupaten OKU Timur.

\begin{tabular}{rlrrr}
\hline \multirow{2}{*}{ No } & \multicolumn{2}{c}{ Jenis } & Nilai & \multicolumn{2}{c}{ Biaya Tetap } \\
\cline { 4 - 5 } & Kebutuhan & Investasi & (Rp/Proses) & $($ Rp/Tahun $)$ \\
\hline 1 & Sewa Lahan & 2.466 .667 & 1.196 .333 & 2.392 .666 \\
2 & Cangkul & 84.667 & 5.133 & 10.266 \\
3 & Sabit & 30.900 & 1.873 & 3.746 \\
4 & Handsprayer & 302.333 & 12.219 & 35.670 \\
5 & Ember & 11.733 & 1.423 & 2.846 \\
6 & Rolli & 344.286 & 7.792 & 15.584 \\
\hline & Jumlah Nilai & 3.240 .586 & 1.224 .774 & 2.460 .778 \\
\hline
\end{tabular}

Sumber : Olahan Data Primer, 2013.
Berdasarkan olahan data primer pada tabel diatas, diperoleh penggunaan biaya investasi awal seperti biaya pembelian lahan usaha dan kelengkapan alat-alat usaha pengelolaan beras semi organik sebelum usaha menghasilkan sebesar Rp 3.240.586,-, dan penggunaan alat-alat pada saat proses produksi hingga menghasilkan rumah knock down yang siap untuk dijual atau disebut sebagai biaya penyusutan alat-alat kerja (Fixed Cost) sebesar Rp 1.224.774,-/proses atau setara dengan $\mathrm{Rp} 2.460 .778$,-/tahun.

\section{b. Analisis Biaya Sarana Usaha}

Penggunaan biaya sarana produksi pada pengelolaan beras semi organik atau biaya tidak tetap (Variabel Cost), berupa penggunaan biaya bahan baku produksi seperti biaya konsumsi, karung, pemanenan, penjemuran dan aplikasi pestisida.. Rata-rata penggunaan biaya sarana usaha pengelolaan beras semi organik di Kabupaten OKU Timur sebagaimana pada tabel berikut:

Tabel 4. Rata-rata Penggunaan Biaya Tidak Tetap Pengelolaan Beras Semi Organik di Kabupaten OKU Timur.

\begin{tabular}{|c|c|c|c|}
\hline \multirow{2}{*}{ No } & \multirow{2}{*}{$\begin{array}{c}\text { Jenis } \\
\text { Kebutuhan }\end{array}$} & \multicolumn{2}{|c|}{ Biaya Sarana Produksi } \\
\hline & & (Rp/Proses) & (Rp/Tahun) \\
\hline \multirow[t]{9}{*}{1} & Kebutuhan Sarana Produksi Tahun Ke 1 & & \\
\hline & a. Jasa traktor & 385.000 & 770.000 \\
\hline & Benih & 66.667 & 133.333 \\
\hline & POG & 202.833 & 405.667 \\
\hline & Pestisida Organik & 67.333 & 134.667 \\
\hline & Nutrisi Buah & 45.833 & 91.667 \\
\hline & POC & 169.333 & 338.667 \\
\hline & Karung & 48.267 & 96.533 \\
\hline & Jumlah & 985.267 & 1.970 .533 \\
\hline \multirow[t]{9}{*}{2} & Kebutuhan Sarana Produksi Tahun Ke 2 & & \\
\hline & a. Jasa traktor & 388.000 & 776.000 \\
\hline & Benih & 66.700 & 133.400 \\
\hline & POG & 202.850 & 405.700 \\
\hline & Pestisida Organik & 68.500 & 137.000 \\
\hline & Nutrisi Buah & 40.000 & 80.000 \\
\hline & POC & 189.500 & 379.000 \\
\hline & Karung & 48.000 & 96.000 \\
\hline & Jumlah & 1.003 .550 & 2.007 .100 \\
\hline \multirow[t]{9}{*}{3} & Kebutuhan Sarana Produksi Tahun Ke 3 & & \\
\hline & a. Jasa traktor & 388.700 & 777.400 \\
\hline & Benih & 67.300 & 134.600 \\
\hline & POG & 203.200 & 406.400 \\
\hline & Pestisida Organik & 68.900 & 137.800 \\
\hline & Nutrisi Buah & 40.700 & 81.400 \\
\hline & POC & 189.900 & 379.800 \\
\hline & Karung & 48.700 & 97.400 \\
\hline & Jumlah & 1.007 .400 & 2.014 .800 \\
\hline \multirow[t]{9}{*}{4} & Kebutuhan Sarana Produksi Tahun Ke 4 & & \\
\hline & a. Jasa traktor & 389.000 & 778.000 \\
\hline & Benih & 67.700 & 135.400 \\
\hline & POG & 203.600 & 407.200 \\
\hline & Pestisida Organik & 69.200 & 138.400 \\
\hline & Nutrisi Buah & 40.900 & 81.800 \\
\hline & POC & 190.200 & 380.400 \\
\hline & g. Karung & 48.900 & 97.800 \\
\hline & Jumlah & 1.009 .500 & 2.019 .000 \\
\hline
\end{tabular}

Sumber : Olahan Data Primer, 2013.

Berdasarkan olahan data primer pada tabel diatas, diperoleh penggunaan biaya sarana usaha seperti pembelian benih dan pestisida organik berbagai jenis dan ukur serta pembelian lainnya. Rata-rata penggunaan biaya sarana (Variabel Cost) pada tahun ke 1 sebesar Rp 985.267,-/proses atau Rp 1.970.533,-/tahun. Pada tahun ke 2 sebesar Rp 1.003.550,-/proses atau Rp 2.007.100,- 
/tahun.Pada tahun ke 3 sebesar Rp 1.007.400,/proses atau Rp 2.014.800,-/tahun. Pada tahun ke 4 sebesar Rp 1.009.500,-/proses atau $\mathrm{Rp}$ 2.019.000,-/tahun, perubahan penggunaan biaya sarana usaha pada setiap tahunnya disebabkan terjadinya kenaikan harga-harga bahan baku yang tidak dapat di hindari oleh para pengusaha pengolahan beras semi organik di Kabupaten OKU Timur.

\section{c. Analisis Biaya Tenaga Kerja}

Tenaga kerja merupakan faktor yang paling penting dalam sebuah usaha, keahlian seorang tenaga kerja dapat menentukan hasil produksi, pada umumnya tenaga kerja di bayar berdasarkan usia dan jenis kelamin. Pada usaha pengelolaan beras semi organik di Kabupaten OKU Timur. Rata-rata penggunaan biaya tenaga kerja pada usaha pengelolaan rumah knock down di Kabupaten OKU Timur sebagaimana pada tabel berikut :

Tabel 5. Rata-rata Penggunaan Biaya Tenaga Kerja Pengelolaan Beras Semi Organik di Kabupaten OKU Timur.

\begin{tabular}{|c|c|c|c|}
\hline \multirow{2}{*}{$\mathrm{No}$} & Jenis & \multicolumn{2}{|c|}{ Biaya Tenaga Kerja } \\
\hline & Tenaga Kerja & (Rpp/Proses) & (Rpp/Tahun) \\
\hline 1 & Tenaga Kerja Tahun Ke 1 & 2.561 .657 & 5.123 .314 \\
\hline 2 & Tenaga KerjaTahun Ke 2 & 2.429 .300 & 4.858 .600 \\
\hline 3 & Tenaga Kerja Tahun Ke 3 & 2.433 .100 & 4.8660 .200 \\
\hline 4 & Tenaga Kerja Tahun Ke 4 & 2.477 .300 & 4.894 .600 \\
\hline
\end{tabular}

Sumber : Olahan Data Primer, 2013.

Berdasarkan olahan data primer pada tabel diatas, rata-rata diperoleh nilai penggunaan tenaga kerja pada tahun ke 1 dengan jumlah hari kerja sebanyak 13 hari denga besaran upah Rp 60.000,/hari denga jumlah tenaga kerja sebanyak 2 tenaga kerja dengan rata-rata biaya tenaga kerja sebesar Rp 2.561.657,-/Proses atau Rp 5.123.314,-/tahun. Pada tahun ke 2 sebesar Rp 2.429.300,-/proses atau $\mathrm{Rp}$ 4.858.600,-/tahun.Pada tahun ke 3 sebesar Rp 2.433.100,-/proses atau Rp 4.866.200,-/tahun dan pada tahun ke 4 sebesar $\mathrm{Rp}$ 2.447.300,/proses atau Rp 4.894.600,-/tahun. Nilai penggunaan tenaga kerja terus meningkat, hal tersebut di sesuaikan dengan keadaan tingginya upah pada umumnya tenaga ahli di wilayah penelitian.

\section{d. Analisis Total Biaya Usaha}

Total biaya adalah jumlah keseluruhan dalam penggunaan biaya suatu usaha yag digunakan untuk mencapai manfaat atau keuntungan, total biaya terdiri dari jumlah biaya tetap, tidak tetap dan biaya tenaga kerja (Total Cost). Rata-rata total biaya yang digunakan pada pengelolaan beras semi organik di Kabupaten OKU Timur sebagaimana pada tabel berikut :

Tabel 6. Rata-rata Total Biaya Usaha Pengelolaan Rumah Knock Down di Kabupaten Ogan Ilir.

\begin{tabular}{|c|c|c|c|}
\hline \multirow{2}{*}{ No } & \multirow{2}{*}{$\begin{array}{c}\text { Jenis Kebutuhan } \\
\text { Biaya }\end{array}$} & \multicolumn{2}{|c|}{ Jumlah Biaya Usaha } \\
\hline & & (Rp/Proses) & (Rp/Tahun) \\
\hline \multirow[t]{5}{*}{1} & Kebutuhan Biaya Tahun Ke 1 & & \\
\hline & Alat Kerja & 1.224 .774 & 2.460 .778 \\
\hline & Sarana Produksi & 985.267 & 1.970 .533 \\
\hline & Tenaga Kerja & 2.561 .657 & 5.123 .314 \\
\hline & Jumlah & 4.771 .697 & 9.554 .625 \\
\hline \multirow[t]{5}{*}{2} & Kebutuhan Biaya Tahun Ke 2 & & \\
\hline & Alat Kerja & 1.224 .774 & 2.460 .778 \\
\hline & Sarana Produksi & 1.003 .550 & 2.007 .100 \\
\hline & Tenaga Kerja & 2.429 .300 & 4.858 .600 \\
\hline & Jumlah & 4.657 .624 & 9.326 .478 \\
\hline \multirow[t]{5}{*}{3} & Kebutuhan Biaya Tahun Ke 3 & & \\
\hline & Alat Kerja & 1.224 .774 & 2.460 .778 \\
\hline & Sarana Produksi & 1.007 .400 & 2.014 .800 \\
\hline & Tenaga Kerja & 2.443 .100 & 4.886 .200 \\
\hline & Jumlah & 4.675 .274 & 9.361 .778 \\
\hline \multirow[t]{5}{*}{4} & Kebutuhan Biaya Tahun Ke 4 & & \\
\hline & Alat Kerja & 1.224 .774 & 2.460 .778 \\
\hline & Sarana Produksi & 1.009 .500 & 2.019 .000 \\
\hline & Tenaga Kerja & 2.447 .300 & 4.894 .600 \\
\hline & Jumlah & 4.681 .574 & 9.374 .378 \\
\hline
\end{tabular}

Sumber : Olahan Data Primer, 2013.

Berdasarkan olahan data primer pada tabel diatas diperoleh rata-rata total biaya yang digunakan pada pengelolaan beras semi organik di Kabupaten OKU Timur, pada tahun ke 1 sebesar $\mathrm{Rp}$ 4.771.679,-/proses atau setara denga Rp 9.554.625,-/tahun, pada tahun ke 2 sebesar Rp 4.657.624,-/proses atau setara dengan $\mathrm{Rp}$ 9.326.478,-/tahun. Pada tahun ke 3 sebesar Rp 4.675.274,-/proses atau setara dengan $\mathrm{Rp}$ 9.361.778,-/tahun dan pada tahun ke 4 sebesar Rp 4.681.574,-/proses atau setara dengan Rp 9.374.378,-/tahun.

\section{Analisis Produksi, Harga, dan Penerimaan Usaha}

Hasil produksi merupakan hasil usaha pengolahan usahatani kopi yang dinyatakan dengan satuan barang yang memiliki harga/nilai jual, sedangkan penerimaan adalah jumlah produksi dalam satuan fisik dikali dengan harga jual persatuan fisik. Penerimaan tunai usahatani didefinisikan sebagai nilai uang yang diterima, besarnya penerimaan yang diperoleh petani dari hasil usahatani antara satu dengan yang lainnya berbeda-beda walaupun luas lahan usaha yang 
Produksi merupakan hasil suatu proses usaha dengan mengelola bahan baku hingga menjadi produk setengah jadi maupun produk jadi yang memiliki nilai jual dan layak untuk dipasarkan, dalam hal ini proses produksi adalah mengolahan bahan baku berupa gabah hingga menjadi produk dalam bentuk beras yang di kemas yang siap untuk dijual. Sedangkan harga jual adalah suatu nilai tukar dari suatu produk yang memiliki nilai jual, dimana nilai atau harga jual terdiri dari penjumlahan biaya-biaya dan nilai tingkat keuntungan yang diinginkan dalam hal ini harga jual beras pada umumnya dihitung berdasarkan luas lahan (Rp/bahu).Sedangkan penerimaan adalah hasil produksi dikali dengan harga jual, dalam hal ini penerimaan diperoleh dari harga jual $(\mathrm{Rp} / \mathrm{Kg})$ dikalikan dengan luas lahan (bahu). Ratarata jumlah produksi, harga jual dan penerimaan pada pengelolaan beras semi organik di Kabupaten OKU Timur sebagaimana pada tabel berikut :

Tabel 7. Rata-rata Jumlah Produksi, Harga Jual dan Penerimaan Pengelolaan Beras Semi Organik di Kabupaten OKU Timur.

\begin{tabular}{|c|c|c|c|}
\hline \multirow{2}{*}{ No } & \multirow{2}{*}{$\begin{array}{c}\text { Uraian } \\
\text { Penerimaan }\end{array}$} & \multicolumn{2}{|c|}{ Jumlah Penerimaan Usaha } \\
\hline & & (Rp/Proses) & (Rp/Tahun) \\
\hline \multirow[t]{4}{*}{1} & Penerimaan Tahun Ke 1 & & \\
\hline & Produksi & 1.038 & \\
\hline & Harga Jual & 9.000 & \\
\hline & Jumlah Penerimaan & 9.342 .000 & 37.368 .000 \\
\hline \multirow[t]{4}{*}{2} & Penerimaan Tahun Ke 2 & & \\
\hline & Produksi & 1.118 & \\
\hline & Harga Jual & 9.000 & \\
\hline & Jumlah Penerimaan & 10.060 .200 & 40.240 .800 \\
\hline \multirow[t]{4}{*}{3} & Penerimaan Tahun Ke 3 & & \\
\hline & Produksi & 1.250 & \\
\hline & Harga Jual & 11.000 & \\
\hline & Jumlah Penerimaan & 13.750 .000 & 55.000 .000 \\
\hline \multirow[t]{4}{*}{4} & Penerimaan Tahun Ke 4 & & \\
\hline & Produksi & 1.700 & \\
\hline & Harga Jual & 12.000 & \\
\hline & Jumlah Penerimaan & 20.400 .000 & 81.600 .000 \\
\hline
\end{tabular}

Sumber: Olahan Data Primer, 2013.

Berdasarkan olahan data primer pada tabel diatas, pada tahun ke 1 rata-rata produksi 1.038/Kg dengan harga jual Rp 9.000,-/Kg, maka perolehan penerimaan sebesar $\mathrm{Rp} 9.342 .000$,/proses atau setara dengan Rp 37.368.000,-/tahun. Pada tahun ke 2 rata-rata produksi $1.118 / \mathrm{Kg}$ dengan harga jual $\mathrm{Rp}$ 9.000, maka perolehan penerimaan sebesar Rp 10.060.200,-/proses atau setara dengan Rp 40.240.800,-/tahun. Pada tahun ke 3 rata-rata produksi $1.250 / \mathrm{Kg}$ dengan harga jual $\mathrm{Rp} 11.000 / \mathrm{Kg}$, maka perolehan penerimaan sebesar Rp 13.750.000,-/proses atau setara dengan
Rp 55.000.000,-/tahun. Pada tahun ke 4 dengan rata-rata produksi 1.700 dengan harga jual $\mathrm{Rp}$ $12.000,-/ \mathrm{Kg}$, maka perolehan penerimaan sebesar $\mathrm{Rp} 20.400 .000,-/$ proses atau setara dengan $\mathrm{Rp}$ $81.600 .000,-/$ tahun.

\section{Analisis Pendapatan dan Keuntungan Usaha}

Pendapatan usaha merupakan selisih antara total penerimaan dengan total biaya. Sedangkan keuntungan dalam hal ini adalah selisih atau hasil pembagian antara total penerimaan dengan total biaya $(\mathrm{R} / \mathrm{C})$.Rata-rata jumlah pendapatan dan tingkat keuntungan $(\mathrm{R} / \mathrm{C})$, pada peng beras semi organik di Kabupaten OKU Timur sebagaimana pada tabel berikut :

Tabel 8. Rata-rata Pendapatan dan Tingkat Keuntungan Pengelolaan Beras Semi Organik di Kabupaten OKU Timur

\begin{tabular}{|c|c|c|c|c|}
\hline \multirow{2}{*}{ No } & \multirow{2}{*}{$\begin{array}{c}\text { Uraian } \\
\text { Pendapatan }\end{array}$} & \multicolumn{2}{|c|}{ Jumlah Pendapatan Usaha } & \multirow{2}{*}{$\begin{array}{c}\text { Keuntungan } \\
(\mathrm{R} / \mathrm{C})\end{array}$} \\
\hline & & (Rp/Proses) & (Rp/Tahun) & \\
\hline \multicolumn{5}{|c|}{1 Pendapatan Tahun Ke 1} \\
\hline & Total Penerimaan & 9.342 .000 & 37.368 .000 & \\
\hline & Total Biaya & 4.771 .697 & 19.086 .790 & \\
\hline & Jumlah Pendapatan & 4.570 .303 & 18.281.210 & 1,96 \\
\hline \multicolumn{5}{|c|}{ Pendapatan Tahun } \\
\hline & Total Penerimaan & 10.060 .200 & 40.240 .800 & \\
\hline & Total Biaya & 4.657 .624 & 18.630 .495 & \\
\hline & Jumlah Pendapatan & 5.402 .576 & 21.610 .305 & 2,16 \\
\hline \multicolumn{5}{|l|}{3} \\
\hline & Total Penerimaan & 13.750 .000 & 55.000 .000 & \\
\hline & Total Biaya & 4.675 .274 & 18.701 .095 & \\
\hline & Jumlah Pendapatan & 9.074 .726 & 36.298 .905 & 2,94 \\
\hline \multicolumn{5}{|c|}{ Pendapatan Tahun Ke 4} \\
\hline & Total Penerimaan & 20.400 .000 & 81.600 .000 & \\
\hline & Total Biaya & 4.681 .574 & 18.726 .295 & \\
\hline & Jumlah Pendapatan & 15.718 .426 & 62.873 .705 & 4,36 \\
\hline
\end{tabular}

Sumber: Olahan Data Primer, 2013.

Berdasarkan olahan data primer pada tabel diatas, usaha pada tahun ke 1 rata-rata diperoleh nilai penerimaan sebesar $\mathrm{Rp}$ 9.342.000,-/Proses dengan penggunaan biaya sebesar $\mathrm{Rp}$ 4.771.679,-/proses maka perolehan pendapatan sebesar Rp 4.570.303,-/proses atau setara dengan Rp18.281.210,-/tahun dengan tingkat keuntungan (R/C) sebesar 1,96 yang artinya setiap $\mathrm{Rp} 1,-$ modal usaha yang digunakan akan memperoleh keuntungan dalam penerimaan sebesar $\mathrm{Rp} 1,96,-$. Usaha pada tahun ke 2 rata-rata diperoleh nilai penerimaan sebesar Rp 10.060.200,-/Proses dengan penggunaan biaya sebesar Rp 4.675.624,/proses maka perolehan pendapatan sebesar $\mathrm{Rp}$ 5.402.576,-/proses atau setara dengan $\mathrm{Rp}$ 4.610.305,-/tahun dengan tingkat keuntungan $(\mathrm{R} / \mathrm{C})$ sebesar 2,16 yang artinya setiap $\mathrm{Rp} 1$,- 
modal usaha yang digunakan akan memperoleh keuntungan dalam penerimaan sebesar Rp 2,16,-. Usaha pada tahun ke 3 rata-rata diperoleh nilai penerimaan sebesar Rp 13.750.000,-/Proses dengan penggunaan biaya sebesar Rp 4.675.274,/proses maka perolehan pendapatan sebesar Rp 9.074.726,-/proses atau setara dengan $\mathrm{Rp}$ 36.290.905,-/tahun dengan tingkat keuntungan (R/C) sebesar 2,05 yang artinya setiap $\mathrm{Rp} 1$,modal usaha yang digunakan akan memperoleh keuntungan dalam penerimaan sebesar Rp 2,94,-. Usaha pada tahun ke 4 rata-rata diperoleh nilai penerimaan sebesar Rp 20.400.000,-/Proses dengan penggunaan biaya sebesar $\mathrm{Rp}$ 4.681.574,/proses maka perolehan pendapatan sebesar Rp 15.718.426,-/proses atau setara dengan Rp 15.718.426,-/tahun dengan tingkat keuntungan $(\mathrm{R} / \mathrm{C})$ sebesar 4,36 yang artinya setiap Rp 1,modal usaha yang digunakan akan memperoleh keuntungan dalam penerimaan sebesar Rp 4,36.

\section{Analisis Tingkat Kelayakan Finansial}

Analisis kelayakan finansial dilakukan untuk mengetauhi apakah usaha yang dilakukan apakah layak dan dapat diteruskan atau tidaknya usaha tersebut, analisis kelayakan finansial yang digunakan pada usaha pengelolaan beras semi organik dapat menggunakan analisis finansial NPV, Net B/C, dan IRR.

Tabel 9. Analisis Tingkat Kelayakan Finansial Usaha Pengelolaan Beras Semi Organik di Kabupaten OKU Timur.

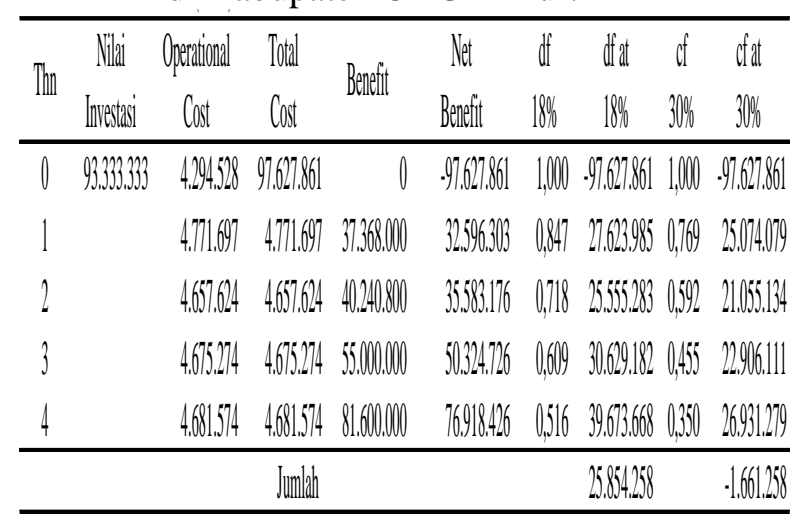

Sumber: Olahan Data Primer, 2013.

- NPV dengan rumus :

$$
\left.\mathrm{NPV}=\left[\sum_{t=i}^{t=n} \frac{b t-c t}{(1+i) t}\right]-K o\right]
$$

NPV (Positif) $18 \%=(27.623 .985+25.555 .283+$ $30.629 .182+39.673 .668)-97.627 .861=$ 25.854 .258
NPV (Negatif) $30 \%=-97.627 .861-$ $(25.074 .079+21.055 .134+22.906 .111+$ $26.931 .279)=-1.661 .258$

$I R R=D F P+\left\{\frac{P V P_{1}}{((P V P)-(P V N))} X(D F N-D F P)\right\}$

Tabel 10. Analisis Internal Rate Returnt (IRR)

\begin{tabular}{lrrrrrr}
\hline NPVP & NPVN & NPVP-NPVN $\frac{\text { NPVP }}{\text { NPVP.NPVN }}$ & $i_{2}$ & $i_{1}$ & $\begin{array}{c}\text { Nilai } \\
\text { IRR }\end{array}$ \\
\hline 25.554 .258 & 1.661 .258 & 27.515 .516 & 0,940 & $30 \%$ & $18 \%$ & $29,28 \%$ \\
\hline
\end{tabular}

Sumber: Olahan Data Primer, 2015

$\mathrm{IRR}=18 \%+(0,940 *(30 \%-18 \%))=29,28$

$\mathrm{Net} \mathrm{B} / \mathrm{C}$ dengan rumus :

$$
\text { Net } \frac{B}{C}=\frac{\sum\left(\sum_{t=1}^{t=n}\left(\frac{b t}{C a+D} \mathrm{~d}\right)\right)}{\left.\sum_{t=i}^{t=n}\left(\frac{c t}{C 1+D t}\right)+K o\right)}
$$

Tabel 11. Analisis Net Benefit (Net B/C)

\begin{tabular}{lll}
\hline NPVP & NPVN & $\begin{array}{c}\text { Net } \\
\text { B/C }\end{array}$ \\
\hline 27.623 .985 & 97.627 .861 & \\
25.555 .283 & & \\
30.629 .182 & & \\
39.673 .668 & & 1,26 \\
\hline 123.482 .119 & 97.627 .861 & \\
\hline
\end{tabular}

Sumber: Olahan Data Primer, 2013.

Net $B / C=123.482 .199 / 97.627 .861=1,26$

Tabel 12. Hasil Analisis Tingkat Kalayak Finansial Pengelolaan Beras Semi Organik di Kabupaten OKU Timur.

\begin{tabular}{llr}
\hline No & Tingkat & \multicolumn{1}{l}{ Nilai } \\
& Kelayakan & Kelayakan \\
\hline 1 Net Present Value (NPV) & \\
& Tingkat Bunga 18\% & 25.854 .258 \\
Tingkat Bunga 30\% & -1.661 .258 \\
2 Internal Rate Retrunt (IRR) & $29,28 \%$ \\
3 Net Benefit per Cost(Net B/C) & 1,26 \\
\hline
\end{tabular}

Sumber: Olahan Data Primer, 2013.

Berdasarkan hasil olahan data primer pada tabel diatas, rata-rata diperoleh nilai NPV Comfounding Faktor terendah 18\% diperoleh nilai sebesar Rp 25.854.258,-/ , pada nilai NPVN Comfounding Faktor 30\% diperoleh nilai negative sebesar - Rp 1.661.258 dengan nilai tingkat bunga yang berlaku kini IRR diperoleh 29,28\% dari SOCC 17\% maka usaha dikategorikan layak 
untuk di usahakan dan dikembangkan, pada analisis tingkat pendapatan atau keuntungan yang telah dikenakan biaya bunga bank Net B/C diperoleh sebesar 1,26, yang artinya usaha masih memberikan keuntungan sebesar 1,26 setelah dikenakan biaya bunga bank.

\section{IV.KESIMPULAN DAN SARAN}

\section{A. Kesimpulan}

Berdasarnya hasil penelitian dan analisis yang telah dilakukan, maka dapat ditarik kesimpulan sebagai berikut:

1. Rata-rata total biaya produksi yang dikeluar Di peroleh usaha pada tahun ke 1 penerimaan sebesar Rp 9.342.000,-/Proses, biaya sebesar $\mathrm{Rp}$ 4.771.679,-/proses maka pendapatan sebesar Rp 4.570.303,-/proses. Usaha pada tahun ke 2 penerimaan sebesar Rp 10.060.200,-/Proses, biaya sebesar Rp 4.657.624,-/proses maka pendapatan sebesar Rp 5.402.576,-/proses. Usaha pada tahun ke 3 penerimaan sebesar Rp 13.750.000,-/Proses, biaya sebesar $\mathrm{Rp}$ 4.675.274,-/proses, maka pendapatan sebesar Rp 9.074.726,-/proses. Usaha pada tahun ke 4 penerimaan sebesar Rp 20.400.000,-/proses, biaya sebesar $\mathrm{Rp}$ 4.681.574,-/proses, maka pendapatan sebesar Rp 15.718.426,-/proses

2. Diperoleh diperoleh nilai NPV Comfounding Faktor terendah 18\% sebesar Rp 25.854.258,/4 tahun, pada nilai NPVN Comfounding Faktor tertinggi 30\%diperoleh nilai negative sebesar - Rp 1.661.258,-/4 tahun dengan IRR diperoleh 29,28\% dan Net B/C diperoleh sebesar 1,26, maka usaha menguntungkan dan layak untuk dikembangkan serta diteruskan.

\section{B.Saran}

Saran yang dapat diberikan dari hasil penelitian yang telah dilakukan adalah:

1. Petani harus memaksimalkan pengelolaan beras semi organik tersebut karena selain bermanfaat bagi kesehatan, ramah lingkungan juga memberikan pendapatan yang lebih di banding beras konvensional.

2. Pemerintah dan petani harus bekerja sama untuk mewujudkan beras organik di Kabupaten OKU Timur agar segera tercapainya sertifikasi.

\section{DAFTAR PUSTAKA}

$\begin{array}{cr}\text { Adminanto. 2001. Konsep } & \text { Biaya } \\ \text { Produksi.http://konsep } & \text { biaya } \\ \text { produksi.blogspot.com. Diakses } & \text { pada } \\ \text { tanggal 5 Oktober 2015. } & \end{array}$

Anonim. 2007. Pola Pertanian Organik. http://pola pertanian organik di Indonesia blogspot.co.id. Diakses pada tanggal 5 Oktober 2015.

Andoko. 2002. Budidaya Padi Secara Organik. Penebar Swadaya. Jakarta.

Dinas Tanaman Pangan dan Hortikultura Bandar Lampung. 2013. SNI Pertanian Organik.blogspot.co.id. Diakses pada tanggal 8 mei 2016.

Haris. 2001. Kebijaksanaan perpajakan untuk pembangunan agribisnis. http: kebijaksanaan perpajakan untuk pembangunan agribisnis.blog-page7. html. Diakses pada tanggal 7 Oktober 2015.

Hernanto. 2004. Ilmu Usaha Tani. Penebar Swadaya. Jakarta.

Kartasapoetra. 2006. Pengantar Ekonomi Produksi. Bina Aksana. Jakarta.

Limbong dan Sitorus. 2001. Rantai Pemasaran. PT. Agromedia. Jakarta.Mubyarto. 2002. Pengantar Ilmu Pertanian. Lembaga penelitian, dan Pendidikan

Nasution. 2004. Konsep Pemasaran. LPP Surabaya. Tiga Serangkai. Jakarta.

Oku Timur Pos. 2012. Surat Kabar Harian. Martapura.

Rahmawan. 2006. Pertanian Semi Organik. Erlangga. Jakarta.

Saragih. 2008. Penggunaan infut Anorganik. Bhineka Cipta. Semarang.

Sjarkowi. 2010. Manajemen pembangunan agribisnis. Baldad Grafiti Press. Palembang

Sjarkowi dan M. Sufri. 2004. Konsep Biaya Produksi dalam usaha tani. Baldad 
Soekartawi. 2001. Pengalokasian sumber daya dalam agoindustri. Tiga Serangkai. Semarang.

Soekartawi dalam ismuwati. 2005. Penerimaan dalam usaha tani. Penebar Swadaya. Jakarta.

Soeprapto. 2002. Waktu Mempengaruhi Harga. Sinar Terang. Jakarta.

Sudarno Sukirno. 2003. Ekonomi Makro, Hukum Permintaan.

Sugiyono. 2004. Pengertian Hukum Penawaran. Rhineka Cipta. Bandung

Suharsimi. 2002. Metode Pengumpulan data dalam observasi. Baldad Grafiti Press. Palembang.

Sujatmiko Eko. 2004.Panca Usaha Tani.http : Blogspot.com/Pertanian Konvensional. Diakses 5 Februari 2016.

Suparno. 2002. Pengertian Penerimaan Secara Umum. Bumi Aksara. Jakarta.

Suratiyah.2006. Biaya produksi untuk keputusan sumber daya.http://biaya produksi untuk keputusan sumber daya.blogspot.com. Diakses pada tanggal 7 Mei 2013.
Susanto. 2001.Komponen yang mempengaruhi pertanian organik. http://komponen yang mempengaruhi pertanian organik. Diakses pada tanggal 7 Juli 2013.

Sutanto. 2002. Pertanian organik sebagai pembangunan agribisnis. Sinar Terang. Surabaya.

Umar. 2000. Studi kelayakan usaha agribisnis. Rhineka Cipta.Bandung.

Walgito. 2009. Metode Penelitian. Karya Cipta. Surabaya.

Winangun. 2004. Konsep agribisnis di Indonesia.http://konsep agribisnis di indonesia.blogspot.com. Diakses pada tanggal 7 Mei 2013.

Zulkarnain. 1993. Perencanaan dan Analisa Proyek.Universitas Indonesia. Jakarta. 